\title{
Dynamics in bacterial cell surface properties assessed by fluorescent stains and confocal laser scanning microscopy
}

\author{
Karen E. Stoderegger*, Gerhard J. Herndl \\ Department of Biological Oceanography, Royal Netherlands Institute for Sea Research (NIOZ), PO Box 59, \\ 1790 AB Den Burg, The Netherlands
}

\begin{abstract}
We investigated the dynamics of hydrophobic and hydrophilic properties of the bacterioplankton cell surface in different life stages, as they may play a crucial role in the uptake of nutrients and in regulating the grazing pressure of potential predators. Bacterial strains were grown in artificial seawater under controlled nutrient conditions and the dynamics of surface properties were assessed by staining living bacteria concurrently with a hydrophobic, a polar and a nucleic acid stain. Mean fluorescence intensity of the individual stain for each single cell was determined using a confocal laser scanning microscope and advanced image analysis. No proportional changes of the hydrophobic or hydrophilic properties with cell size were detectable, indicating their independence of cell size. While hydrophobic properties remained fairly constant and exhibited species-specificity, the polarity of the surface was more dependent on the life stage of free-living cells. Bacterial cells assembling in aggregates, however, exhibited a small but distinct elevated hydrophobicity compared to free-living cells. Based on their hydrophobicity, 2 distinctly different groups of bacteria could be distinguished. One group of bacterial strains exhibited a continuous increase in the ratio of hydrophilicity to hydrophobicity, whereas the less hydrophobic group exhibited 2 peaks in the ratio hydrophilicity to hydrophobicity. This ratio was significantly lower for the less hydrophobic group, indicating that less hydrophobic bacteria are also less hydrophilic. Increased growth rates were found with higher cell surface hydrophobicity. This might be interpreted as an expression of 2 different life strategies in bacterioplankton. Increased hydrophobicity and concomitant increase of polar moieties facilitate nutrient assimilation and seem to be advantageous for bacteria adapted to high nutrient environments maximizing growth at higher grazing losses. In contrast, bacteria with lower hydrophobicity exhibit a lower assimilation efficiency with reduced grazing pressure.
\end{abstract}

KEY WORDS: Bacteria - Confocal laser scanning microcopy - CLSM - Cell surface charge · Hydrophobicity $\cdot$ Hydrophilicity $\cdot$ Bacterial cell wall

\section{INTRODUCTION}

Bacterioplankton represent the largest living surface in the world's ocean, and bacteria interact with their environment via their surface. It is now commonly acknowledged that most bacterioplankton exhibit a bacterial capsule, at least in certain phases of their life cycle. Bacteria with an intact intracellular structure maintain a capsular envelope attached to the cell wall (Heissenberger et al. 1996), consisting of highly hydrated polysaccharides (Bayer \& Bayer 1994), which are released in the stationary phase of growth (Kennedy \& Sutherland 1987, Decho 1990, Stoderegger \& Herndl 1998). Actively growing cells constantly renew parts of the capsular envelope (Stoderegger \& Herndl 1998). Extensive capsular production can also be the result of nutrient limitation. For example, Pseudoalteromonas sp. produces a hydrophobic capsule in dilute medium while in rich medium no capsular envelope is formed (Singh \& Vincent 1987). 
The bacterial cell envelope consists of acidic mucopolysaccharides (Luft 1971). Hydrophilic sites are composed of positively charged amino groups and negatively charged carboxyl-, phosphate- and guanidyl-groups (Noda \& Kanemasa 1986, Tzianabos et al. 1993). Lipids and lipopolysaccharides represent the hydrophobic sites of the bacterial cell surface. High molecular weight polysaccharides can exhibit either one hydrophobic region at one end of the polysaccharide molecule (amphiphilic polymers) or hydrophobic groups are distributed across the entire molecule (polyphilic polymers) (Neu 1996). Lipopolysaccharides are typically amphiphilic polymers in Gram-negative bacteria (Neu 1996). The bacterial polyphilic polymers are polysaccharides containing either deoxy sugars or other hydrophobic components such as acyl, methyl and similar groups. Probably the best known example of bacterial polyphilic polysaccharides are the 6-deoxy sugars fucose and rhamnose as well as $N$-acetylhexosamines (Neu 1996). However, other deoxy sugars might also be responsible for the hydrophobic character of the polysaccharides (Kenne \& Lindberg 1983).

The interspecific variability of the surface properties of bacteria in natural communities and the dynamics between hydrophobicity and hydrophilicity in different life stages and nutrient conditions are still largely unknown. Meno \& Fujimoto (2002) report the presence of hydrophobic capsules in 5 Escherichia coli strains, while strains without capsules were hydrophilic. Contrary to these findings, capsules of actively growing bacteria have also been shown to be highly hydrophilic (Rosenberg et al. 1983, Bayer \& Bayer 1994). Dyar \& Ordal (1948) reported lower electrophoretic mobility of exponentially growing bacterial strains while increased hydrophobicity was related to high growth rates by other authors (Malmqvist 1983, Van Loodsrecht et al. 1987). A decreasing hydrophobicity of marine bacterioplankton was reported to coincide with lower substrate availability and increasing depth of the water column (Monger et al. 1999). Büchs et al. (1988) related increased hydrophilicity to nutrient limitation and exponential growth (Lemke et al. 1995). Increased exopolymer production was found in specific bacterial strains during starvation (Dawson et al. 1981, Wrangstadh et al. 1990). A concurrent increase of hydrophobic and hydrophilic properties (Stenström \& Kjelleberg 1985) facilitates particle attachment of bacteria (Fletcher \& Loeb 1979, Stenström \& Kjelleberg 1985). Jana et al. (2000) found significant differences in the intraspecific variability of the hydrophobicity of the cell surface in 18 marine isolates of Pseudomonas fluorescens.

Common techniques to measure the hydrophobic and/or hydrophilic properties such as bacterial adhesion, contact angle measurements or spectroscopy- based methods require extensive manipulation of the cells including filtration, dehydration or centrifugation prior to analysis (Pembrey et al. 1999). These cell manipulations might modify the physicochemical properties of the specific organisms (Rosenberg \& Doyle 1990, Pembrey et al. 1999).

We used a non-destructive, minimally manipulative cell surface analysis technique to determine the hydrophobic and hydrophilic moieties of marine bacteria. Using this method we relate the surface properties to other characteristics of the bacterial cell (i.e. cell size). As charge is an important property of the bacterial surface, we hypothesize that surface properties are related to the overall metabolic activity of the cell. By comparing different bacterial strains, potential interspecific differences in cell surface properties (i.e. hydrophobic and hydrophilic) were investigated and related to nutrient availability and, hence, growth conditions.

\section{MATERIALS AND METHODS}

Sample preparation and quantification of the hydrophobic and hydrophilic moieties of the bacterial cell surface. The hydrophobic and hydrophilic parts of the bacterial cell surface were detected by applying a combination of 3 fluorescent dyes to the samples collected on the filter and subsequent confocal laser scanning microscopy (CLSM, Zeiss 510). As a polar tracer, Alexa Fluor 594 hydrazide (Molecular Probes, A-10442) was used. To stain hydrophobic regions, a stock solution of $0.25 \%$ of Dil $\mathrm{C}_{18}(5)$ oil (Molecular Probes, D-307) in dimethylformamide was applied. Additionally, PicoGreen (Molecular Probes, P-7581) was used for detection of the bacterial genome. All 3 stains were stored frozen $\left(-20^{\circ} \mathrm{C}\right)$ in small quantities and exposure to light was avoided during handling. Prior to applying the dyes to the bacterial samples, the aliquots of the stock solutions were brought to room temperature. For each filtered sample, a working solution of $300 \mu \mathrm{l}$ distilled water with $1.5 \mu \mathrm{l}$ of each of the stock solutions of the 3 stains added was prepared and thoroughly vortexed. Depending on the expected abundance of the bacteria, 0.5 to $20 \mathrm{ml}$ of sample was filtered onto $0.2 \mu \mathrm{m}$ Anodisc membrane filters (Whatman, $25 \mathrm{~mm}$ diameter) and rinsed with $0.5 \mathrm{ml}$ of distilled water to remove salts. Then, the working solution was applied and the sample was left in the dark for 15 min. Subsequently, the sample was rinsed again twice with $0.5 \mathrm{ml}$ of distilled water. The filter was transferred to a glass slide, embedded in immersion oil (Citifluor, AF1) and covered with a cover slip. Within $2 \mathrm{~h}$, the stained sample was examined under the CLSM. Multitrack laser scanning (frame mode) was 
used to avoid fluorescence overlapping and a PlanNeofluar $100 \times 1.3$ oil objective for image acquisition. For the detection of the PicoGreen-stained cells, an Argon laser (488 nm wavelength) was used and signal detection was achieved using a BP 505-530 filter. For AlexaFluor 594, the HeliumNeon-1 laser (543 nm) and BP 585-615 filter were applied and for Dil $\mathrm{C}_{18}(5)$ the HeliumNeon-2 laser ( $633 \mathrm{~nm}$ ) and the LP 650 filter.

For the different experimental setups, detector and amplitude gain and amplitude offset were adjusted once and the laser intensities standardized as described below. Therefore, for each experiment, only the laser intensities were re-adjusted for each image to ensure that the gray-scale of the images never exceeded 256 (image depth: 8 Bit).

For image analysis, the Zeiss KS 300 software package was used. On the combined 3-channel image, the area of each individual bacterial cell was determined and, subsequently, the threshold levels for the 3 channels were adjusted globally for this area according to Sieracki et al. (1985). Visual threshold determinations with standard beads revealed that the bead size we obtained was only slightly larger than that specified by the manufacturer (see 'Discussion'). The images were checked for detected cells and eventually corrected by excluding particles or adding cells originally not detected by the channel settings. The total area resulting from the 3 different stains in the combined image as well as the areas detected by the 3 channels and the mean fluorescence intensity for each of the 3 channels were determined. The mean fluorescence intensity of the specific stain represents the average fluorescence covering the specific area normalized to $100 \%$ laser intensity. Per sample, a total of 15 images (10 to 30 bacteria per image) was taken.

The hydrophobic and hydrophilic properties of individual cells are expressed as IND $_{\text {prop. This index }}$ relates the area of the hydrophobic or hydrophilic property to its mean fluorescence intensity. It was calculated for each property separately and 'prop' stands for hydrophilic or hydrophobic property of the individual bacterial cell. IND prop was calculated as follows:

$$
\mathrm{IND}_{\text {prop }}=\left(\mathrm{D}_{\text {prop }} / \mathrm{D}_{\text {prop,ave }}\right) \times \mathrm{AR}_{\text {prop }}
$$

where $D_{\text {prop }}$ and $A R_{\text {prop }}$ are the mean fluorescence intensity and the specific area (expressed as percentage of total area) of the individual cell, respectively, and $D_{\text {prop,ave }}$ is the mean fluorescence intensity of all the cells examined on the filters. As fluorescence intensity is not an absolute value, we standardized the laser intensity to the average fluorescence of the analyzed bacteria to become independent of the applied lasers and to be able to compare the variation of fluorescence intensities of the different stains. As different beads were used for standardization of the lasers and the fluorescence intensity of the beads was not always similar to the fluorescence intensity of the bacterial strains, a standardization with microspheres would have made it impossible to compare different lasers and, consequently, staining properties.

To include cells lacking fluorescence indicative for a specific property (i.e. hydrophobic and hydrophilic) in the assessment of the total bacterial community, we calculated:

$$
\mathrm{COM}_{\text {prop }}=\left(\mathrm{IND}_{\text {prop,ave }} \times \mathrm{N}_{\text {prop }}\right) / \mathrm{N}_{\text {tot }}
$$

where $\mathrm{N}_{\text {prop }}$ is the number of bacteria exhibiting the specific property and $\mathrm{N}_{\text {tot }}$ is the total number of bacteria at a specific time point during growth in the batch

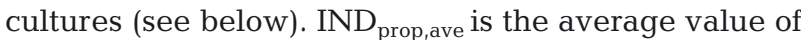
$\mathrm{IND}_{\text {prop }}$ at this time point for the bacterial strain derived from Eq. (1). A COM prop of 100 would therefore indicate a community where the whole area of the individual cells is occupied by the specific property (i.e. hydrophobic or hydrophilic) exhibiting the average of the mean fluorescence intensity per cell.

Additionally, the ratio between hydrophilic and

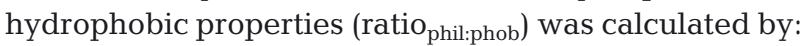

$$
\text { ratio }_{\text {phil:phob }}=\mathrm{COM}_{\text {hydrophilic }} / \mathrm{COM}_{\text {hydrophobic }}
$$

Standard preparation. The stability of the laser over time and the linearity of the fluorescence signal with increasing laser intensity was checked with standard fluorescent beads (InSpeck, $\Phi=2.5 \mu \mathrm{m}, 0.3 \%$ relative fluorescence, Molecular Probes, I-7219, I-7224, I-7225). These fluorescent beads were tested under the specific CLSM settings at the beginning and at about half way through the analysis using the single track option from the lowest (min. gray scale $>20$ ) to the highest possible laser intensity (max. gray scale 256). For the Argon laser $(488 \mathrm{~nm})$, InSpeck Green (excitation/emmission [Ex/Em]: 505/515 nm), for the HeliumNeon-1 laser $(543 \mathrm{~nm})$ InSpeck Red (Ex/Em: 580/605 nm), and for the HeliumNeon-2 laser (633 nm) InSpeck Deep Red (Ex/Em: 633/660 nm) were used. For the 4 different settings, the correlation coefficients of the linear regression for the 3 different standard fluorescent beads varied between $r^{2}=0.93$ and $0.99(n=219$ to 629$)$.

Experimental setup to follow changes of the surface properties of bacteria over time. To determine the interspecific variability of bacterial surface properties, 6 Gram-negative marine strains (Pseudoalteromonas caragenovora isolated from marine snow collected in the Adriatic Sea, Rhodobacter azotoformans isolated from the North Sea, Vibrio viscosus from the North Atlantic, Pseudoalteromonas sp. ANG.ro2 from the South Atlantic, Alteromonas atlantica, and Pseudomonas libaniensis) as well as and 1 Gram-positive strain (Arthrobacter agilis) were used. The strains were partially sequenced in our laboratory, and were 
cultured in ZoBell 2216 broth (5 g of peptone, $1 \mathrm{~g}$ of yeast extract, 11 of sterilized artificial seawater). A total of 3 experiments per strain was performed. Additionally, 1 experiment under phosphorus limitation was done with the strains A. agilis, Pseudoalteromonas sp. ANG.ro2 and P. caragenovora. To $1 \mathrm{l}$ of artificial seawater, $100 \mu \mathrm{M}$ C of glucose-D (final conc.), $10 \mu \mathrm{M} \mathrm{N}$ in the form of $\mathrm{NH}_{4}{ }^{+} \mathrm{Cl}^{-}$and $1 \mu \mathrm{M} \mathrm{P}$ as $\mathrm{NaH}_{2} \mathrm{PO}_{4}{ }^{3-}$ were added to obtain a final C:N:P ratio of 100:10:1 for the nutrient-replete cultures. For the P-limited cultures, $100 \mu \mathrm{M} \mathrm{C}$ (final conc.) of glucose-D and $10 \mu \mathrm{M} \mathrm{N}$ in the form of $\mathrm{NH}_{4}{ }^{+} \mathrm{Cl}^{-}$were added. About 2 to $3 \times 10^{6}$ cells were added as inoculum. Bacteria were allowed to grow at $18^{\circ} \mathrm{C}$ in the dark until the senescent phase was reached (after about $1 \mathrm{wk}$ ) and samples were taken daily to determine the hydrophobic and hydrophilic properties of individual bacterial cells during growth of the culture. The sample volume was adjusted to collect 1 to $3 \times 10^{6}$ bacteria per filter. Bacterial abundance was determined by fixing 1 to $10 \mathrm{ml}$ of sample with formaldehyde ( $2 \%$ final conc.) and staining with DAPI (Porter \& Feig 1980). Subsequently, the sample was filtered onto a black polycarbonate filter (Millipore, 0.2 pore size) and enumerated under an epifluorescence microscope (Zeiss, Axioplan). Bacterial abundance was determined at a magnification of $1250 \times$ and a minimum of 300 bacteria was counted per filter.

\section{RESULTS}

\section{Evaluation of the method used to discriminate hydrophobic from hydrophilic parts of the bacterial cell surface}

Cells of cultured strains (Fig. 1A) were usually much larger than cells of natural bacterial communities (Fig. 1B). Below, only results from strains are presented. The surface properties of natural bacterioplankton communities will be presented in a subsequent paper (Stoderegger \& Herndl unpubl.). Hydrophilic areas were usually smaller than hydrophobic areas, and nonhydrophilic cells were encountered more frequently than non-hydrophobic cells. This is probably due to the fact that the hydrophobic stain binds to the lipid bilayer of the cell wall, the lipopolysaccharides of the outer membrane and the capsule, while the hydrophilic stain targets only the latter 2 surface moieties. Cells not stained by PicoGreen are probably 'ghost cells' lacking a stainable genome (see Fig. 1A,B). Cells were usually stainable with at least 2 dyes.

Fig. $1 \mathrm{C}-\mathrm{K}$ shows a scan through different focus planes ( $z$-scan). It is obvious that there is no overlap between the channels used to detect the different stains as some highly hydrophobic bacteria hardly exhibited hydrophilic and genome properties during the scan through the focus planes (compare Fig. 1A and B). One bacterium depicted in Fig. 1C-K showed 3 hydrophobic 'hot spots', which were not detectable in the other channels used to assess the hydrophilic and genome properties. Scanning along the z-axis was not done routinely, however, due to the rapid fading of the stains and the time-consuming data acquisition and manipulation. The plane usually taken for measurements is shown in Fig. 1G, i.e. the image with the most distinct cell boundaries determined by visual examination.

\section{Interspecific variability of individual surface properties of the bacterial cell}

To determine the interspecific variability of the cell surface properties, the data collected from the 3 replicate experiments per strain were pooled. The mean strain-specific values for the different properties were determined (Fig. 2) and related to each other and to cell size (Table 1). Overall, about $80 \pm 5 \%$ of all the cells of the different strains used in these experiments were detected by PicoGreen, only Pseudoalteromonas caragenovora lacked stainable DNA more often (61\% detectable with PicoGreen). About $88 \pm 9.4$ and $64 \pm$ $17.1 \%$ of all the cells from the different strains showed hydrophobic and hydrophilic moieties, respectively (Fig. 2A). For all bacterial cells analyzed, the standard deviation for the cell size was $64 \%$ of the mean, for the hydrophilic property $71 \%$, and for the hydrophobic and genome property it was 27 and $30 \%$, respectively. The standard deviation for hydrophilic and hydrophobic mean fluorescence intensities was 32 and $33 \%$ of the mean, respectively. The equivalent spherical diameter (ESD), calculated from the total cell size,

Fig. 1. Visualization of bacterial cells stained with the different fluorescence tracers to assess hydrophobic and hydrophilic properties of the cell surface by confocal laser scanning microscopy. (A) and (B) are divided into 4 parts representing the 3 channels and the composite image. Hydrophobic properties are displayed in red (upper left), hydrophilic properties in yellow (lower left), the genome properties in green (upper right), and the composite image is also shown (lower right). Red arrows indicate hydrophobic, yellow arrows hydrophilic and green arrows genome areas of the cell. White arrows show cells stained with all 3 tracers. Typical examples are shown in (A) for a bacterial strain (Pseudoalteromonas sp. ANG.ro2), in (B) for a natural bacterial community collected from the coastal North Sea in April 2002, and in (C-K) a $Z$-scan of Pseudoalteromonas sp. ANG.ro2 is shown ( $z$-slice: $0.4 \mu \mathrm{m})$. Magnification: $3000 \times(\mathrm{A}, \mathrm{B})$ and $8000 \times(\mathrm{C}-\mathrm{K})$. Scale bars $=2 \mu \mathrm{m}(\mathrm{A}, \mathrm{B})$ and $5 \mu \mathrm{m}(\mathrm{C}-\mathrm{K})$ 

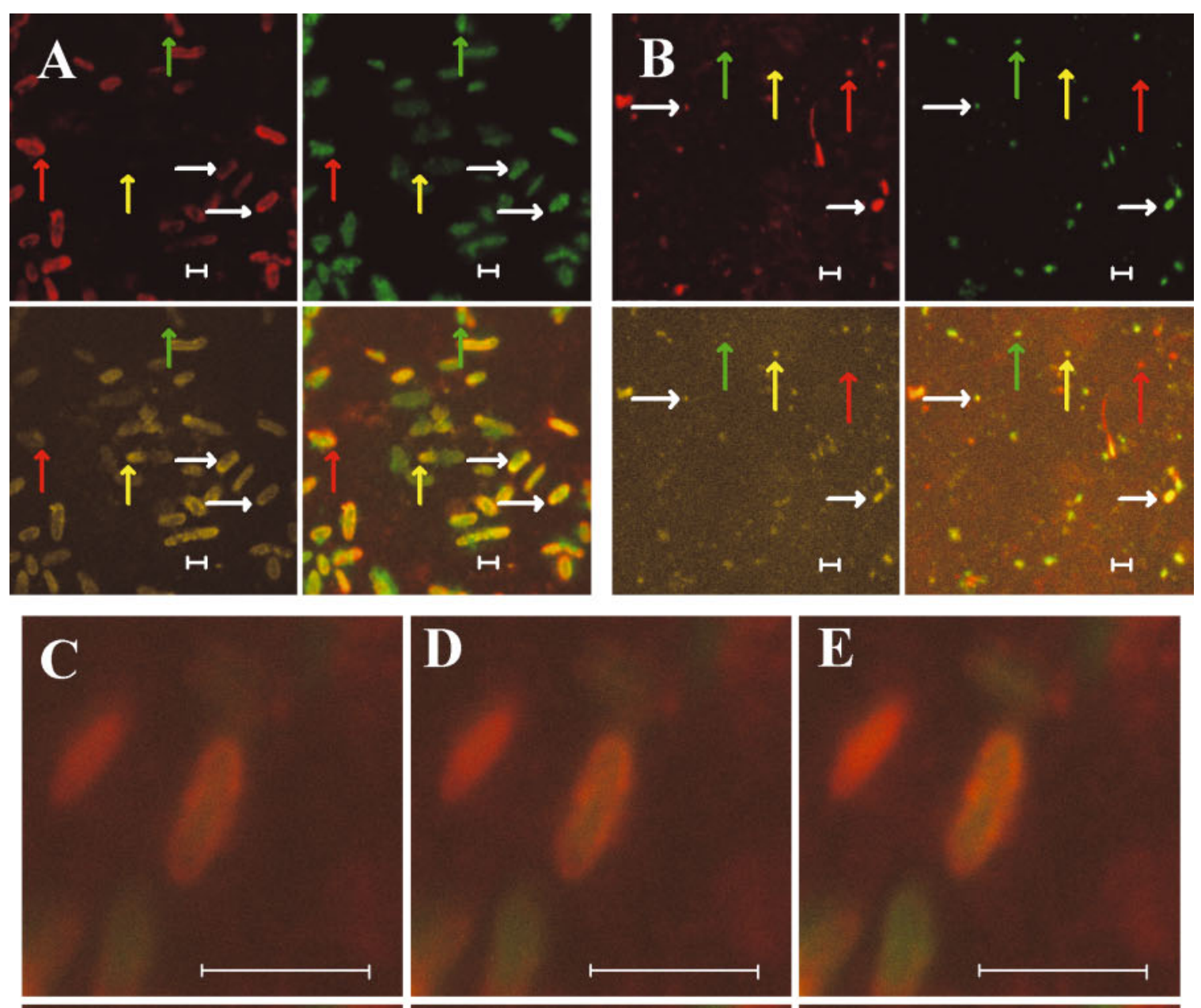

E
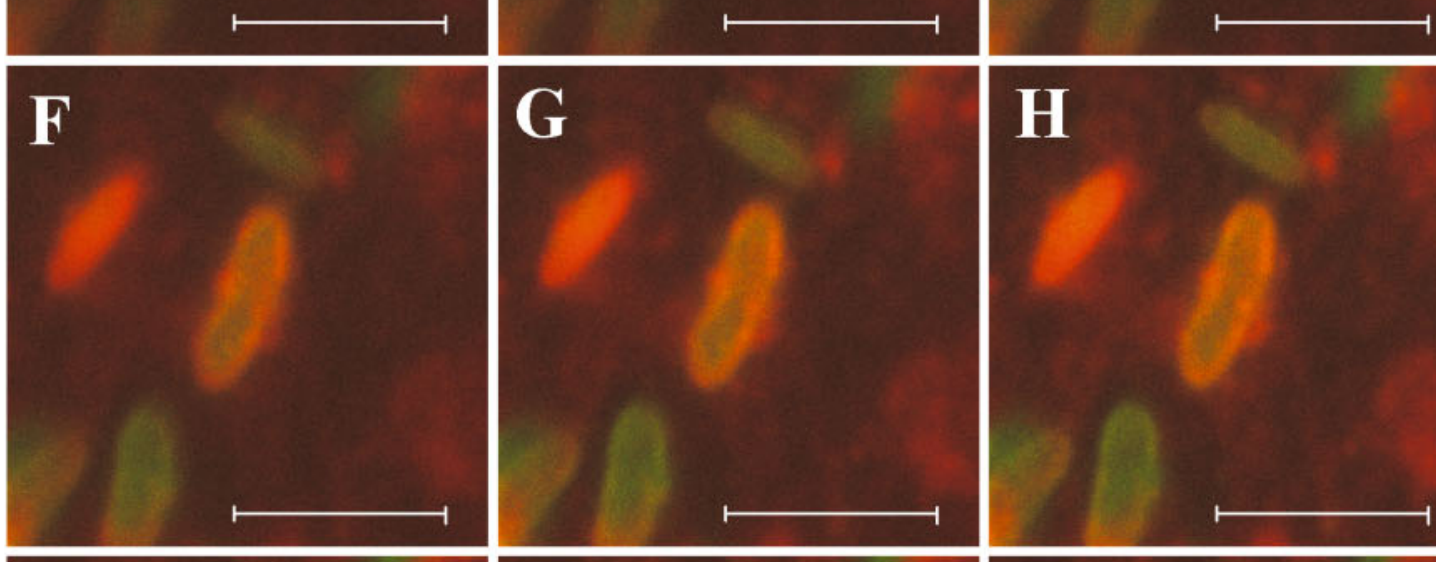

\section{H}

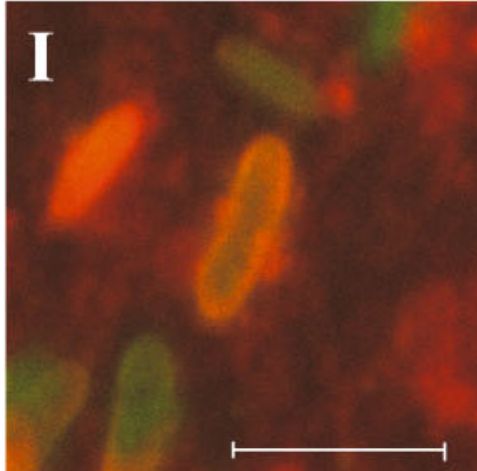

\section{$\mathbf{J}$}

K 

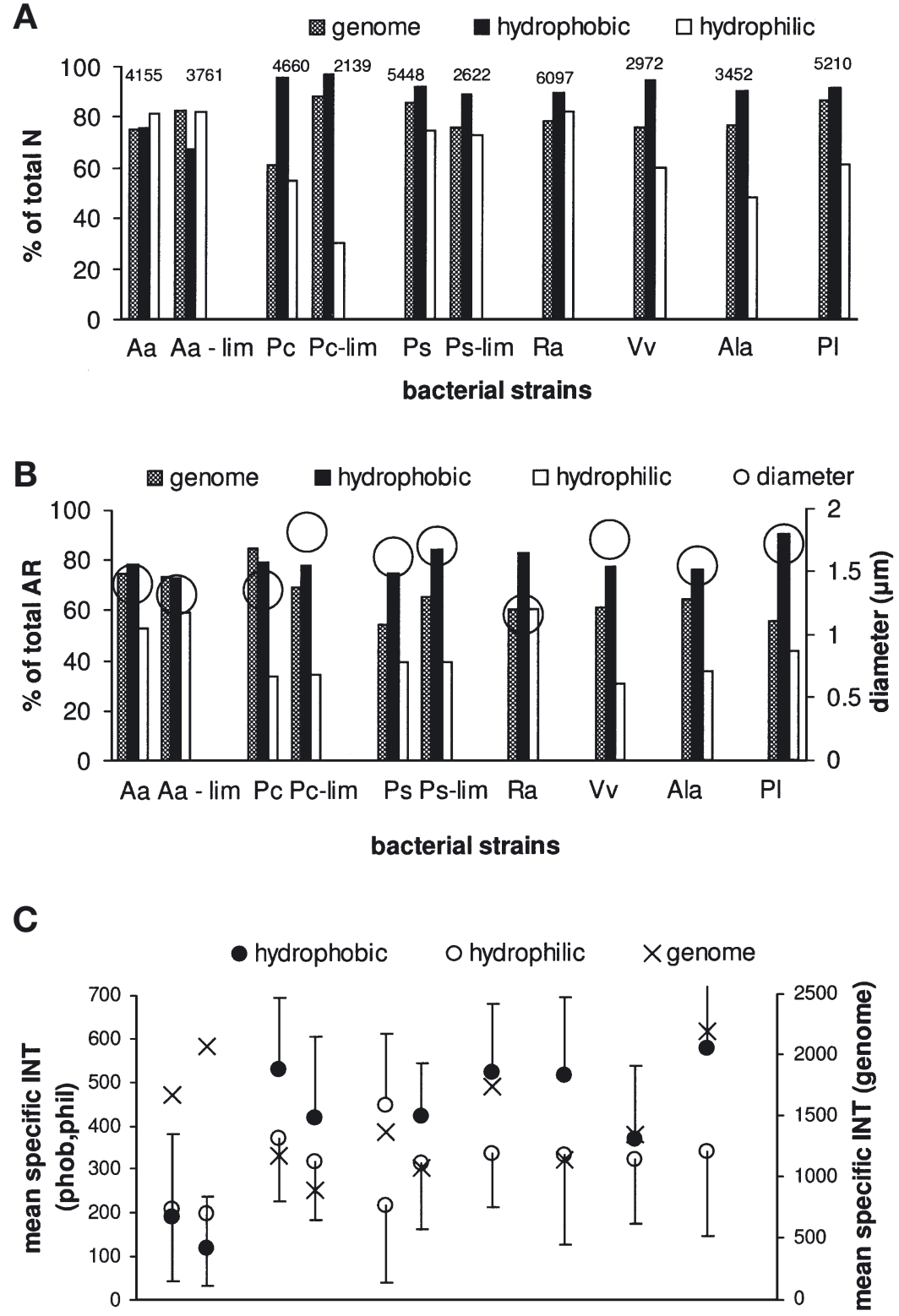

Aa Aa-lim Pc Pc-lim Ps Ps-lim Ra Vv Ala PI

\section{bacterial strains}

Fig. 2. Hydrophobic, hydrophilic and genome properties of individual bacterial strains averaged over the growth phase in batch cultures. (A) Percentage of cell number exhibiting the specific property (i.e. genome, hydrophobic or hydrophilic) and the total number of bacterial cells per strain analyzed are given (total number of cells analyzed per property, i.e. hydrophobic or hydrophilic, ranged from 2139 to 6097). (B) Average percentage of the area covered by a property (i.e. genome, hydrophilic and hydrophobic) in relation to the total area and, for comparison, the average diameter of the total area for all the cells of the specific strains (open circles) are given. (C) Average of the mean specific fluorescence intensity per property is shown; 1-sided error bars indicate the positive standard deviation for the hydrophobic and the negative standard deviation for the hydrophilic property. N: number of counts; AR: area; INT: mean fluorescence intensity. Bacterial strains: Aa, Arthrobacter agilis; Pc, Pseudoalteromonas caragenovora; Ps, Pseudoalteromonas sp. ANG.ro2; $\mathrm{Ra}$, Rhodobacter azotoformans; Vv, Vibrio viscosus; Ala, Alteromonas atlantica; $\mathrm{Pl}$, Pseudomonas libaniensis; lim, phosphorus limited ranged between 1.16 and $1.81 \mu \mathrm{m}$ for the different bacterial strains (Fig. 2B). For Gram-negative strains, the ESD was significantly higher in the P-limited cultures than in the nutrient-replete cultures and was $1.81 \pm 1.35$ and $1.36 \pm$ $1.09 \mu \mathrm{m}$, respectively, for $P$. caragenovora and $1.7 \pm 1.36$ and $1.61 \pm 1.26 \mu \mathrm{m}$ for Pseudoalteromonas sp. (Fig. 2B, 2-group $t$-test, both $\mathrm{p}<0.01, \mathrm{n}=4660$ and 2139 for $P$. caragenovora and $\mathrm{n}=$ 5448 and 2622 for Pseudoalteromonas sp.). In contrast, the Gram-positive strain Arthrobacter agilis exhibited an ESD of $1.40 \pm 1.17$ and $1.32 \pm 1.04 \mu \mathrm{m}$ for P-limited and balanced nutrient regimes, respectively (Fig. 2B, 2-group t-test, both $\mathrm{p}<0.01, \mathrm{n}=3761$ and 4155). Rhodobacter azotoformans was, on average, the smallest among all the bacterial strains examined, with an ESD of $1.16 \pm 0.95 \mu \mathrm{m}$ (Fig. 2B). The ESD of the bacterial strains was significantly different from each other, except for Pseudomonas libaniensis and Pseudoalteromonas sp. under P-limited conditions (2-group $t$-test, $\mathrm{p}>0.01, \mathrm{n}=5210$ and 2622). Pooling all the strains, the genome covered, on average, $66 \pm 9 \%$ of the total cell area, with highest values for P. caragenovora (84\%) and lowest values for Pseudoalteromonas sp. (54\%, Fig. 2B). On average, the hydrophobic property covered $79 \pm 5 \%$ (between $90 \%$ for P. libaniensis and $74 \%$ for Pseudoalteromonas sp.) of the total cell area (Fig. 2B). The hydrophilic area covered $43 \pm 11 \%$ (range: $60 \%$ for R. azotoformans and $30 \%$ for Vibrio viscosus, Fig. 2B). Compared to the other strains, the Gram-positive strain ( $A$. agilis) showed highest genome mean fluorescence intensity, while hydrophobic and hydrophilic properties exhibited the lowest fluorescence intensities of all the strains tested (Fig. 2C). The genome mean fluorescence intensities for the 2 P-limited Gram-negative strains were lower than for the corresponding non-limited strains. The same pattern was detectable for the hydrophobic mean fluorescence intensities for these cultures, but not for the hydrophilic mean fluorescence intensities (Fig. 2C). Genome mean fluorescence 
Table 1. Correlation analysis between the specific total cell area and the specific moieties. The increase of the slopes $(k)$ of the different bacterial species for the pooled data sets is given. (A) The slope ( $k$ ) between the total cell area (cell AR) and the area and the intensity of the specific moieties. (B) The slope $(k)$ between the area and the mean fluorescence intensity of the specific moiety. PHOB: hydrophobic; PHIL: hydrophilic; DNA: genome; AR: area; INT: mean fluorescence intensity. All the significance levels are $\mathrm{p}<0.01$, ns: not significant. Bold values: $\mathrm{r}^{2}>0.5$; bold values with ${ }^{*}$ : $0.5>\mathrm{r}^{2}>0.4$. Aa: Arthrobacter agilis; Pc: Pseudoalteromonas caragenovora; Ps: Pseudoalteromonas sp. ANG.ro2; Ra: Rhodobacter azotoformans; Vv: Vibrio viscosus; Ala: Alteromonas atlantica; Pl: Pseudomonas libaniensis; lim: phosphorus limited

\begin{tabular}{|c|c|c|c|c|c|c|c|c|c|c|c|}
\hline (A) & Cell AR & Ps-lim & Aa-lim & $\mathrm{PC}_{\mathrm{C}}$ & Ps & Ala & $\mathrm{Aa}$ & $\mathrm{Pl}$ & $\mathrm{Vv}$ & $\mathrm{Ra}$ & Pc-lim \\
\hline & PHOB AR & 0.77 & 0.79 & 0.73 & 0.77 & 0.64 & 0.72 & 0.87 & 0.72 & 0.78 & 0.7 \\
\hline & PHIL AR & 0.21 & $0.50^{*}$ & $0.36^{*}$ & $0.26^{*}$ & 0.66 & $0.34^{*}$ & $0.23^{*}$ & 0.13 & $0.41^{*}$ & 0.22 \\
\hline & DNA AR & 0.8 & 0.75 & 0.64 & 0.70 & 0.72 & 0.75 & 0.58 & $0.39^{*}$ & $0.52^{*}$ & 0.63 \\
\hline & PHOB INT & 47.9 & 36.3 & -20 & 41.1 & 8.04 & 16.8 & 98.3 & 47.0 & 78.1 & 51 \\
\hline & PHIL INT & 41.4 & 17.9 & -50 & 59.1 & 12.2 & 7.12 & 26.7 & -12 & 23.3 & -16 \\
\hline & DNA INT & -186 & -9.1 & 37.1 & -103 & -130 & -92 & 214 & 332 & 156 & 159 \\
\hline (B) & AR-INT & Ps-lim & Aa-lim & Pc-lim & Ps & Ala & $\mathrm{Aa}$ & $\mathrm{Pl}$ & $\mathrm{Vv}$ & $\mathrm{Ra}$ & Pc \\
\hline & РHOB & 57.6 & 56.4 & 58.2 & 55.9 & 21.1 & 34.2 & 115 & 47.7 & 97.1 & $-367^{*}$ \\
\hline & PHIL & 32.3 & ns & ns & -23 & 38.7 & -11 & ns & 103 & -19 & -28 \\
\hline & DNA & -237 & -87.3 & $-41^{*}$ & -299 & -219 & -151 & 379 & 98.6 & 80.5 & -154 \\
\hline
\end{tabular}

intensity was not significantly different between $P$. caragenovora and V. viscosus and between Pseudoalteromonas sp. and Alteromonas atlantica (2-group $t$-test, $\mathrm{p}>0.01, \mathrm{n}=4660,2972,5448$, and 4155 for $P$. caragenovora, V. viscosus, Pseudoalteromonas sp., and A. atlantica, respectively). Hydrophobic mean fluorescence intensities were similar for $V$. viscosus and $R$. azotoformans (2-group $t$-test, $\mathrm{p}>0.01, \mathrm{n}=2972$, 6097). All the other strains were significantly different from each other for genome and hydrophobic intensities (2-group $t$-test, $\mathrm{p}<0.01)$. No interspecific differences in the hydrophilic mean fluorescence intensities were detectable (Fig. 2C).

With increasing cell size, the genome area as well as the hydrophobic and the hydrophilic areas increased. This increase, as indicated by the slope of the linear regression $(k)$, was, on average, 0.33 and was lowest for the hydrophilic area ( $k=0.13$ to 0.66$)$, and more than twice as high for the genome $(k=0.65 \pm 0.12)$ and hydrophobic area $(k=0.75 \pm 0.06$, see also Table $1 \mathrm{~A})$. Genome mean fluorescence intensity decreased with genome area (in 7 out of 10 cases). In contrast, hydrophobic mean fluorescence intensity increased with increasing hydrophobic area $\left(\mathrm{r}^{2} \approx 0.3\right.$, all strains), while hydrophilic mean fluorescence intensity was independent of its area (Table 1B). Comparing individual bacterial strains, essentially identical relations between hydrophobic area and cell size were found for Pseudoalteromonas caragenovora, Vibrio viscosus, Arthrobacter agilis and for Pseudoalteromonas sp., P-limited Pseudoalteromonas sp., Rhodobacter azotoformans and the P-limited $A$. agilis (comparison of homogeneity of slope, $\mathrm{p}>0.1$ ). The relation between hydrophilic area and cell size was similar for P-limited P. caragen- ovora, Pseudomonas libaniensis and P-limited Pseudoalteromonas sp. as well as for Pseudoalteromonas sp. and $P$. libaniensis. The genome to cell size relation was similar for $P$. caragenovora and $A$. agilis, as well as for Pseudoalteromonas sp. and Alteromonas atlantica.

Hydrophobic mean fluorescence intensity related to cell size for Vibrio viscosus, P-limited Pseudoalteromonas caragenovora, P-limited Pseudoalteromonas sp., P-limited Arthrobacter agilis and Pseudoalteromonas sp. showed no significant difference in the slope (comparison of homogeneity of slope, $p>0.1$ ). The relation between genome mean fluorescence intensity and total cell size was similar for P-limited $P$. caragenovora and Rhodobacter azotoformans, for Pseudoalteromonas sp. and $A$. agilis and, for Alteromonas atlantica and Plimited Pseudoalteromonas sp. Hydrophilic mean fluorescence intensities were not related to cell size $\left(\mathrm{r}^{2} \approx 0.2\right.$ for the different strains, data not shown). Comparison of the relation between area and mean fluorescence intensity of the different properties among different strains, P. caragenovora, Pseudoalteromonas sp., Plimited Pseudoalteromonas sp., and P-limited A. agilis, was not significantly different regarding hydrophobic fluorescence, and $P$. caragenovora and $A$. agilis as well as $R$. azotoformans and $V$. viscosus were not significantly different regarding genome fluorescence.

\section{Dependence of surface properties on cell size}

To relate hydrophobic and hydrophilic areas to the corresponding mean fluorescence intensities, the relative indices, IND $\mathrm{I}_{\text {hydrophobic }}$ and $\mathrm{IND}_{\text {hydrophilic }}$ (Eq. 1), for the individual cells were determined. Subsequently, 
these indices were related to total bacterial cell size. If percent values for the area were used in Eq. (1), changes in hydrophobic and hydrophilic properties were found to be independent of bacterial cell size (correlation, $\mathrm{r}^{2}=0.04, \mathrm{n}=12637 ; \mathrm{r}^{2}<0.01, \mathrm{n}=6817$ for hydrophobic and hydrophilic properties, respectively). If absolute values were used, however, hydrophobic and hydrophilic indices increased with cell size (data not shown). The overall higher $\mathrm{IND}_{\text {hydrophobic }}$ than IND $D_{\text {hydrophilic }}$ indicates that hydrophilic areas were smaller than hydrophobic areas.

\section{Bacterial cell surface properties for individual populations}

In the above considerations, single bacterial cells exhibiting a specific property (i.e. hydrophobic or hydrophilic) were assessed. To evaluate the properties of entire populations, including those cells not exhibiting a specific property at a certain time point during the course of growth in the batch culture, we calculated the specific community indices (Eq. 2) $\mathrm{COM}_{\text {hydrophobic }}$ and $\mathrm{COM}_{\text {hydrophilic }} \mathrm{COM}_{\text {hydrophobic }}(75.38 \pm$ 25.67) was usually higher (Fig. 3) than $\mathrm{COM}_{\text {hydrophilic }}$ $(15.99 \pm 15.7)$, a pattern already found on a single cell basis. For Arthrobacter agilis, large variations in both $\mathrm{COM}_{\text {hydrophobic }}$ and $\mathrm{COM}_{\text {hydrophilic }}$ were detectable (Fig. 3), attributable to the tendency of this strain to form aggregates. As A. agilis was the only Gram-

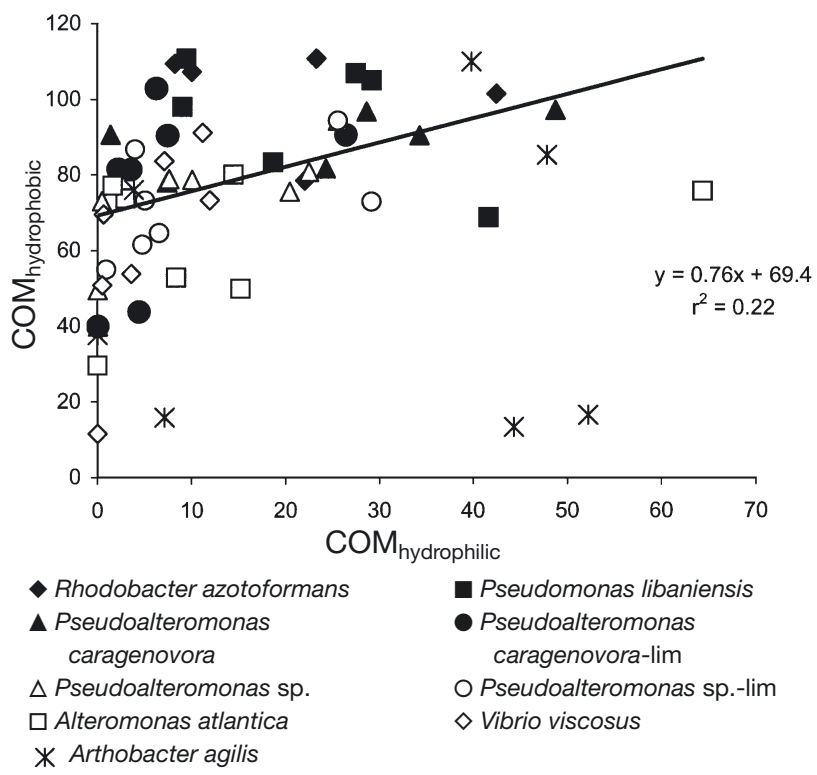

Fig. 3. Relation between the hydrophilic $\left(\mathrm{COM}_{\text {hydrophilic }}\right)$ and hydrophobic $\left(\mathrm{COM}_{\text {hydrophobic }}\right)$ properties on the population level for the different strains at specific time points. For the regression slope, data of the Gram-positive Alteromonas agilis are excluded $\left(r^{2}=0.22, p<0.01, n=47\right)$. lim: phosphorus limited positive strain in our experiment, we focus in the subsequent analysis on the Gram-negative strains. $\mathrm{COM}_{\text {hydrophilic }}$ was linearly related to $\mathrm{COM}_{\text {hydrophobic }}$ $\left(r^{2}=0.22, p<0.01, n=47\right.$, Fig. 3$)$ and to bacterial abundance $\left(\mathrm{r}^{2}=0.14, \mathrm{p}<0.01, \mathrm{n}=47\right)$, while $\mathrm{COM}_{\text {hydrophobic }}$ was not correlated to bacterial abundance $\left(\mathrm{r}^{2}=0.04\right.$, $\mathrm{p}>0.01, \mathrm{n}=47$ ).

Based on the calculated $\mathrm{COM}_{\text {hydrophobic }}$ values for the individual bacterial strains we were able to distinguish 3 groups of bacteria. One group of bacterial strains clustering around a $\mathrm{COM}_{\text {hydrophobic }}$ value of 70 (73 \pm 12 , $69 \pm 11,68 \pm 13$ and $64 \pm 29$ for Pseudoalteromonas sp., P-limited Pseudoalteromonas sp., Alteromonas atlantica and Vibrio viscosus, respectively), the other group around 100 (102 \pm 10 and $98 \pm 15$ for Pseudomonas libaniensis and Rhodobacter azotoformans, respectively) and Pseudoalteromonas caragenovora at $89 \pm 8$ and $82 \pm 20$ growing under nutrient replete and $\mathrm{P}$-limitation conditions, respectively. The $\mathrm{COM}_{\text {hydrophobic }}$ values for each cluster were significantly different from each other (Kolmogorov-Smirnov, $\mathrm{p}<0.01, \mathrm{n}=14$, 15, 31) (Fig. 3).

\section{Development of the bacterial surface properties in different growth stages}

To determine whether hydrophilicity or hydrophobicity prevails in different life stages, the ratio of the fluorescence indicative for hydrophilicity and hydro-

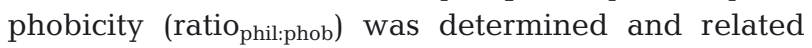
to the corresponding growth stages. The ratio ${ }_{\text {phil:phob }}$ showed a large variation over the different growth stages. The 2 more hydrophobic bacterial clusters (Fig. 4A) showed a more variable pattern over time (comparison of slope, $\mathrm{p}=0.04, \mathrm{n}=48$ ) than the less hydro-

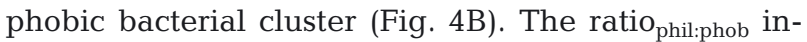
creased more or less continuously from the exponential to the stationary phase (linear regression, $\mathrm{r}^{2}=0.48, \mathrm{n}=$ 24 ) in the more hydrophobic bacterial strains (Fig. 4A). The less hydrophobic bacterial strains, however, showed 2 distinct peaks, one around the late exponential phase/beginning stationary phase and another one in the late stationary/senescent phase $\left(\mathrm{r}^{2}=0.37, \mathrm{n}=24\right.$, Fig. 4B). The slopes of the 2 groups were significantly different from each other and the ratio ${ }_{\text {phil:phob }}$ was significantly higher $(0.20 \pm 0.14)$ for the more hydrophobic than for the less hydrophobic bacterial strains $(0.14 \pm$ 0.18 ) (2-group $t$-test, $\mathrm{p}=0.037, \mathrm{n}=48$ ). Excluding the $\mathrm{P}$ limited Pseudoalteromonas caragenovora culture as a potentially fast growing strain, bacterial abundance of the more hydrophobic strains was significantly higher than of the less hydrophobic strains (2-group $t$-test, $\mathrm{p}=$ $0.007, \mathrm{n}=18$ to 24 ); however, the development of the slopes was similar (comparison of slopes, $\mathrm{p}=0.7, \mathrm{n}=24$ ). 


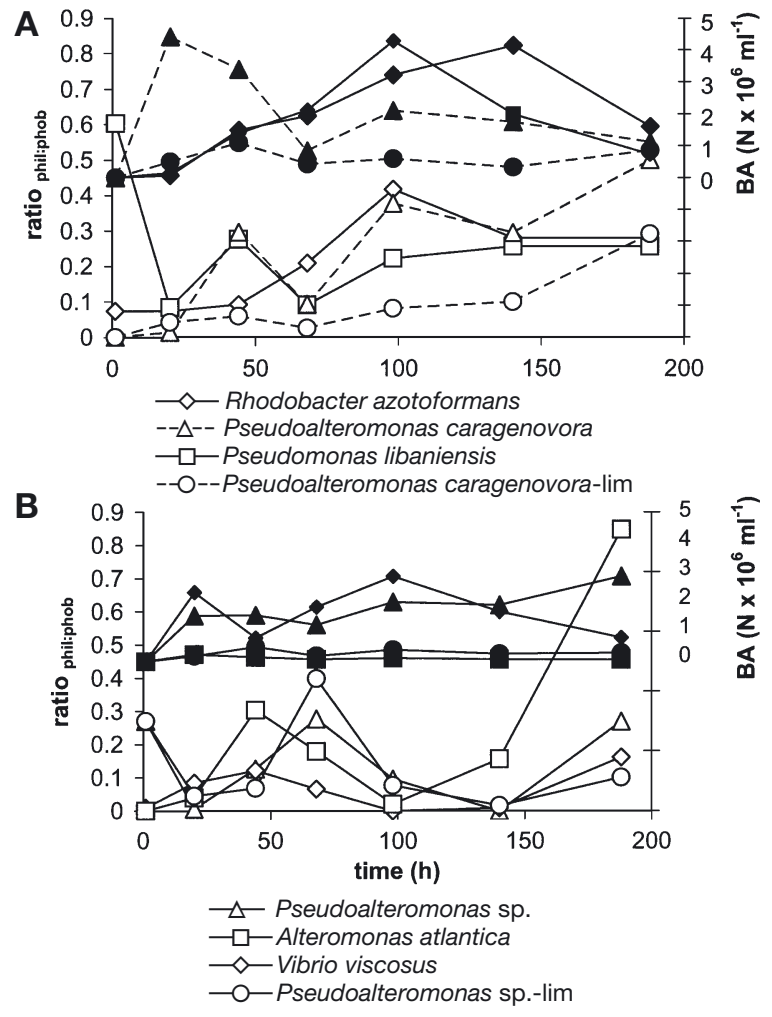

Fig. 4. Development of the ratio ${ }_{\text {phil:phob }}\left(\mathrm{COM}_{\text {hydrophilic: }}\right.$ $\mathrm{COM}_{\text {hydrophobic }}$ ) (open symbols) and bacterial abundance (BA) (closed symbols) for (A) more hydrophobic and (B) less hydrophobic bacterial strains (as described in detail in the text) over time. Slopes of regression are significantly different between (A) and (B) for the ratio phil:phob but not for BA

\section{DISCUSSION}

\section{Evaluation of the method}

By using 2 fluorescent stains for tracing surface properties, we were able to simultaneously measure the hydrophobicity and polar moieties of the bacterial cell surface. Rosenberg \& Doyle (1990) concluded that the use of molecular probes to assess cell surface property is superior over measuring bacterial adhesion. One major drawback of our method might be that such probes eventually intercalate within the cell envelope and may bind to sites not only located at the outermost cell surface but also intracellularly. The molecular size of the stains used in this study (Alexa Fluor 594 hydrazide: $760 \mathrm{Da} \mathrm{DiIC}_{18}(5)$ oil: $\left.960 \mathrm{Da}\right)$ is slightly higher than the average size of molecules which can pass the Gram-negative bacterial cell wall ( 600 Da) (Payne 1980, Weiss et al. 1991). Thus, we assume that the stains used in this study predominantly stain the lipopolysaccharides of the cell surface.

As pretreatment of the samples is minimized with the method presented here, the risk of major losses or changes of the outermost cell surface is low. We obtained relative fluorescence values for specific properties and area values indicate the total cell area covered by the specific property. Due to the lack of an absolute unit for hydrophobicity, essentially all studies on the hydrophobicity of bacterial cell surfaces used relative units, making comparison of different methods difficult. Therefore, the determined variation in fluorescence can only be compared within this investigation and no external standard was applied. To allow comparison among different samples, the setting of the detector and amplitude gain and amplitude offset remained unchanged during the whole investigation and calibrated with microspheres, which were also used for size calibration. The calibration of the laser with microspheres at selected intervals is commonly used with image-analysis and laser scanning microscopy (Viles \& Sieracki 1992, Rijstenbil et al. 2000).

For area detection with the CLSM, Sieracki et al. (1989) found that the visual threshold determination, as used in this study, tends to overestimate the threshold, causing an underestimation of microsphere size. These authors reported an overestimation of the actual cell size (in their case Synechococcus sp.) for the smallest and brightest fluorescing cells only. As cells tend to fade towards the edges (see also Fig. 1), the outermost areas might not be accurately detectable with our method, especially if the central part is intensively stained. This might have resulted in a slight underestimation of the actual cell size. The microspheres we used (2.5 $\mu \mathrm{m}$ diameter) for standardization usually indicated that we slightly overestimated their size $(\sim 2.7 \pm 0.2 \mu \mathrm{m}$, for all the different beads).

\section{Bacterial ghost cells}

It has been shown that total counts of marine bacteria include a large fraction of non-nucleoid-containing bacteria (Zweifel \& Hagström 1995), these 'ghost cells' were considered to be residues of virus-lysed bacteria or remains of protozoan grazing. There is some consensus now that not all of the bacteria present in the aquatic environment are metabolically active or alive. The abundance of this 'ghost cell' fraction varies between 20 and $80 \%$ in natural communities depending on the method used to determine this fraction. A significant number of these ghost cells developed a visible nucleoid within $6 \mathrm{~h}$ after the addition of nutrients (Choi et al. 1996). If the size and shape of the area covered by the hydrophobic or hydrophilic properties appeared like a typical bacterium, it was classified as such even if there was no stainable genome present. Apparently, even in the exponential growth phase of some cultured bacteria not all the bacteria exhibit 
a stainable genome. This was most pronounced in Pseudoalteromonas caragenovora, a bacterium isolated from marine snow. P. caragenovora grows fast under nutrient-replete conditions (see also Fig. 4) and, in the absence of grazers, a part of the population becomes inactive, i.e. it loses its stainable genome.

\section{Individual surface properties and cell size}

We found that the bacterial genome covers about 60 to $70 \%$ of the total bacterial cell area (Fig. 2B); thus genome size increases with cell size, if absolute sizevalues are used. The same holds true for hydrophobic and hydrophilic properties (Table 1). However, no major changes in the corresponding mean fluorescence intensities with total cell size, were detectable (Table 1), indicating that the expression of hydrophobic and hydrophilic properties is not dependent on cell size. Related to this, we recently showed that the formation of a capsular envelope is independent of the cell size as well, (Stoderegger \& Herndl 2001), even very small bacteria can produce an extensive capsule. However, a small genome size does not always imply a small cell size. Pseudomonas libaniensis exhibits a small genome and a fairly large cell size (Fig. 2B). Nevertheless, cell size increases with increasing genome size and the area occupied by the hydrophobic property $\left(k=0.58, k=087, \mathrm{r}^{2}>0.5\right.$, Table $\left.1 \mathrm{~A}\right)$.

\section{Bacterial life strategies}

The development of hydrophobic and hydrophilic properties is highly dynamic and influenced by various factors. Bacteria with elevated hydrophobic properties also exhibit elevated hydrophilic properties and bacterial hydrophobicity is mainly species-dependent (Fig. 3). More hydrophobic bacteria showed a more

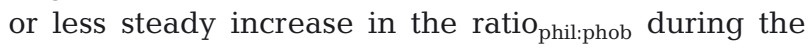
life cycle while less hydrophobic bacteria showed 2 distinct peaks (Fig. 4). This distinct pattern might be a response to the nutrient availability in the cultures by these bacterial strains. We assume that hydrophilic properties of the bacterial cell are mainly related to nutrient availability, as hydrophilicity was not straindependent but varied according to growth stage in our study. Hydrophobicity plays a central role in adhesion to surfaces. Investigating different bacterial strains, increased fimbriation was clearly correlated with increased adhesion and the presence of fimbriae is associated with increased hydrophobicity and negative surface charge; positive charge increases as well, but to a smaller degree (Stenström \& Kjelleberg 1985).
Although the 2 groups distinguished based on their hydrophobicity (the more and the less hydrophobic bacterial strains) exhibited similar growth rates, the more hydrophobic bacterial strains reached a higher abundance. The less hydrophobic strains that reached a lower abundance were isolated from the open Atlantic Ocean, while the strains that exhibited higher hydrophobicity were isolated from environments with a high nutrient load in the water column (coastal North Sea, coastal Adriatic Sea, Pseudoalteromonas caragenovora directly from marine snow), except Pseudomonas libaniensis (South Atlantic). Lemke et al. (1995) measured the uptake rate of different phosphate compounds in hydrophobic and hydrophilic (=less hydrophobic) bacterial strains. Overall, hydrophobic bacteria reached a higher abundance than hydrophilic bacteria and were able to utilize hydrophobic and hydrophilic organic and inorganic phosphate, whereas hydrophilic bacteria were less efficient in the uptake of hydrophobic organic phosphate compounds. Furthermore, the presence of extracellular phosphatase activity in hydrophobic cells was demonstrated (Lemke et al. 1995) and it was shown that not the lack of enzymes but the unavailability of the substrate to the enzyme was growth limiting. Büchs et al. (1988) showed that Corynebacterium glutamicum is hydrophobic under phosphate-replete conditions and tends to flocculate and adhere to glass surfaces. Bacteria adapted to more nutrient-replete conditions seem to be able to effectively utilize the available nutrients and express increased surface hydrophobicity and hydrophilicity.

\section{Hydrophobicity and grazing}

For the water column of the subtropical Pacific, Monger et al. (1999) showed that the hydrophobicity of Prochlorococcus sp. declined rapidly below $80 \mathrm{~m}$ depth and the abundance of heterotrophic bacteria decreased slightly but steadily with depth and from more mesotrophic to more oligotrophic conditions. They showed that bacteria with the highest hydrophobicity were also grazed more efficiently by nanoflagellates. For highly hydrophobic bacterial strains, Gurijala \& Alexander (1990) concluded that the advantage of more efficient growth prevails over the disadvantage of higher grazing mortality. In contrast, Matz \& Jürgens (2001) did not find any correlation between grazing rates of flagellates and the surface charge of their bacterial prey. Theoretical considerations on the thermodynamic mechanism of phagocytosis also suggest that hydrophobicity should result in enhanced grazing rates (Van Oss et al. 1975, Monger \& Landry 1990).

In summary, we may conclude that the more hydrophobic bacterial strains are better adapted to high 
nutrient conditions. Bacteria adapted to low nutrient conditions have lower growth rates, a high substrateaffinity but lower substrate demand, while bacteria with increased hydrophobic and hydrophilic properties invest energy in surface properties in order to maximize substrate utilization and compensate the higher grazing losses by elevated growth rates.

Acknowledgements. We thank Christian Winter and Jesus Maria Arrieta for supplying the bacterial strains. Financial support was provided by the Royal NIOZ, by a Schrödinger post-doctoral grant from the Austrian Science Foundation (FWF) to K.E.S and by the BASICS project within the 5th framework program of the European Commission.

\section{LITERATURE CITED}

Bayer ME, Bayer MH (1994) Biophysical and structural aspects of the bacterial capsule. Am Soc Microbiol News 4:192-198

Büchs J, Mozes N, Wandrey C, Rouxhet PG (1988) Cell adsorption control by culture conditions. Influence of phosphate on surface properties, flocculation and adsorption behavior of Corynebacterium glutamicum. Appl Microbiol Biotechnol 29:119-128

Choi JW, Sherr EB, Sherr BF (1996) Relation between presence-absence of a visible nucleoid and metabolic activity in bacterioplankton cells. Limnol Oceanogr 41(6): 1161-1168

Dawson MP, Humphrey BA, Marshall KC (1981) Adhesion: a tactic in the survival strategy of a marine Vibrio during starvation. Curr Microbiol 6:195-199

Decho AW (1990) Microbial exopolymer secretions in ocean environments: their role(s) in food webs and marine processes. Oceanogr Mar Biol Annu Rev 28:73-153

Dyar MT, Ordal EJ (1948) Electrokinetic studies on bacterial surfaces. I. The effects of surface-active agents on the electrophoretic mobilities of bacteria. J Bacteriol 56: 149-167

Fletcher M, Loeb GI (1979) Influence of substratum characteristics on the attachment of a marine pseudomonad to solid surface. Appl Environ Microbiol 37:67-72

Gurijala KR, Alexander M (1990) Effect of growth rate and hydrophobicity on bacteria surviving protozoan grazing. Appl Environ Microbiol 56:1631-1635

Heissenberger A, Leppard GG, Herndl GJ (1996) Relationship between the intracellular integrity and the morphology of the capsular envelope in attached and free-living marine bacteria. Appl Environ Microbiol 62:4521-4528

Jana TK, Srivastava AK, Csery K, Arora DK (2000) Influence of growth and environmental conditions on cell surface hydrophobicity of Pseudomonas fluorescens in nonspecific adhesion. Can J Microbiol 46:28-37

Kenne L, Lindberg B (1983) Bacterial polysaccharides. In: Aspinall GO (ed) The polysaccharides. Academic Press, New York, p 287-363

Kennedy AFD, Sutherland IW (1987) Analysis of bacterial exopolysaccharides. Biotechnol Appl Biochem 9:12-19

Lemke MJ, Churchill PF, Wetzel RG (1995) Effect of substrate and cell surface hydrophobicity on phosphate utilization in bacteria. Appl Environ Microbiol 61:913-919

Luft JH (1971) Ruthenium red and violet. I. Chemistry, purification, methods of use for electron microscopy and mechanism of action. Anat Rec 171:347-368
Malmqvist $\mathrm{T}$ (1983) Bacterial hydrophobicity measured as partition of palmitic acid between the 2 immiscible phases of cell surface and buffer. Acta Pathol Microbiol Immunol Scand Sect B 91:69-73

Matz C, Jürgens K (2001) Effects of hydrophobic and electrostatic cell surface properties of bacteria on feeding rates of heterotrophic nanoflagellates. Appl Environ Microbiol 67: $814-820$

Meno Y, Fujimoto S (2002) Characteristics of capsules in enterotoxemic E. coli O139:K12 strains causing swine edema disease. Microbiol Res 157:1-5

Monger BC, Landry MR (1990) Direct-interception feeding by marine zooflagellates: the importance of surface and hydrodynamic forces. Mar Ecol Prog Ser 65:123-140

Monger BC, Landry MR, Brown SL (1999) Feeding selection of heterotrophic marine nanoflagellates based on the surface hydrophobicity of their picoplankton prey. Limnol Oceanogr 44:1917-1927

Neu TR (1996) Significance of bacterial surface active compounds in interaction of bacteria with interfaces. Microbiol Rev 60:151-166

Noda Y, Kanemasa Y (1986) Determination of hydrophobicity on bacterial surfaces by nonionic surfactants. J Bacteriol 167:1016-1019

Payne JW (1980) Transport and utilization of peptides by bacteria. In: Payne JW (ed) Microorganisms and nitrogen sources. John Wiley \& Sons, Chichester, p 212-256

Pembrey R, Marshall KC, Schneider RP (1999) Cell surface analysis techniques: what do cell preparation protocols do to cell surface properties? Appl Environ Microbiol 65: $2877-2894$

Porter KG, Feig YS (1980) The use of DAPI for identifying and counting aquatic microflora. Limnol Oceanogr 25:943-948

Rijstenbil JW, Coelho SM, Eijsackers M (2000) A method for the assessment of light-induced oxidative stress in embryos of fucoid algae via confocal laser scanning microscopy. Mar Biol 137:763-774

Rosenberg E, Gottlieb A, Rosenberg M (1983) Inhibition of bacterial adherence to hydrocarbons and epithelial cells by emulsan. Infect Immun 39:1024-1028

Rosenberg M, Doyle RJ (1990) Microbial cell surface hydrophobicity: history, measurement, and significance. American Society for Microbiology, Washington, DC

Sieracki ME, Johnson PW, Sieburth JM (1985) Detection enumeration and sizing of planktonic bacteria by imageanalyzed epifluorescence microscopy. Appl Environ Microbiol 49:799-810

Sieracki ME, Reichenbach SE, Webb KL (1989) Evaluation of automated threshold selection methods for accurately sizing microscopic fluorescent cells by image analysis. Appl Environ Microbiol 55:2762-2772

Singh KK, Vincent WS (1987) Clumping characteristics and hydrophobic behavior of an isolated bacterial strain from sewage sludge. Appl Microbiol Biotechnol 25:396-398

Stenström TA, Kjelleberg S (1985) Fimbria mediated nonspecific adhesion of Salmonella typhimurium to mineral particles. Arch Microbiol 143:6-10

Stoderegger K, Herndl GJ (1998) Production and release of bacterial capsular material and its subsequent utilization by marine bacterioplankton. Limnol Oceanogr 43:877-884

Stoderegger KE, Herndl GJ (2001) Visualization of the exopolysaccharide bacterial capsule and its distribution in oceanic environments. Aquat Microb Ecol 26:195-199

Tzianabos AA, Onderdonk AB, Rosner B, Cisneros RL, Kasper DL (1993) Structural features of polysaccharides that induce intra-abdominal abscesses. Science 262: $416-419$ 
Van Loodsrecht MCM, Lyklema J, Norde W, Schraa G, Zehnder AJB (1987) The role of bacterial cell wall hydrophobicity in adhesion. Appl Environ Microbiol 53: 1893-1897

Van Oss CJ, Gillman CF, Neumann AW (1975) Phagocytic engulfment and cell adhesiveness as cellular phenomena. Dekker, New York

Viles CL, Sieracki ME (1992) Measurement of marine picoplankton cell size by using a cooled, charge-coupled device camera with image-analyzed fluorescence microscopy. Appl Environ Microbiol 58(2):584-592

Editorial responsibility: David Karl,

Honolulu, Hawaii, USA
Weiss MS, Abele U, Weckesser J, Welte W, Schiltz E, Schulz GE (1991) Molecular architecture and electrostatic properties of a bacterial porin. Science 254:1627-1630

Wrangstadh M, Szewzyk U, Östling J, Kjelleberg S (1990) Starvation-specific formation of a peripheral exopolysaccharide by a marine Pseudomonas sp., strain S9. Appl Environ Microbiol 56:2065-2072

Zweifel UL, Hagström Å (1995) Total counts of marine bacteria include a large fraction of non-nucleoid-containing bacteria (Ghosts). Appl Environ Microbiol 61(6): 2080-2185

Submitted: March 17, 2003; Accepted: March 15, 2004 Proofs received from author(s): June 18, 2004 